\title{
Design of Handphone Wireless Charger System Using Omnidirectional Antenna
}

\author{
Anton Yudhana, Fahrizal Djohar \\ Electrical Engineering Department, Universitas Ahmad Dahlan, \\ Jalan Prof. Dr. Soepomo, Janturan, Umbulharjo Yogyakarta, Telp.: 0274-563515, Indonesia \\ *Corresponding author, e-mail: eyudhana@ee.uad.ac.id, fahrizaldjohar@ee.uad.ac.id
}

\begin{abstract}
Using cable as power transmission medium cause problem in flexibility and aesthetics. Wireless power transmission for charging handphone releasednowadays still using antenna with radiation pattern focus in one direction, that is just toward the top, and if the antenna was shifted then power transmitted will be lose. The purpose of this research is to produce wireless power charger system used for charging handphone power using resonator based on omnidirectional antenna and test the performance.

The device in this research was designed in two main part, that is transmitter and receiver. In transmission section, there is power supply used for supplying power to oscillator to generate oscillating signal in the form of electrical power to be transmitted to receiver via antenna in the form magnetic field. In receiver section, receiver antenna received the power transmitted that is still in the reach of magnetic field generated by transmitter. The power that is still in the form of oscillating signal, then stabilized for the purpose of handphone power using rectifier and voltage regulator.

Design has been made successfully to the form of handphone battery power wireless chargerusing omdirectional antenna which consist of two main part, that is transmitter and receiver. The transmitted power is 3.058 watt with frequency $714 \mathrm{KHz}$, and receiver received the power and then stabilized the signal to produce output power 58.706 miliwatt. This device can transmit power in all directions horizontally (angle $360^{\circ}$ ). This device also tested with some kind of obstacle, with the result almost all obstacle still could transmit the power except metal.
\end{abstract}

Keywords: Handphone, Wireless Power Transfer, Resonance, Omnidirectional, Oscillator

Copyright $@ 2017$ Universitas Ahmad Dahlan. All rights reserved.

\section{Introduction}

\subsection{Background}

Electric energy become a life necessity in everyday life, especially in facilitating the work associated with power tools or electronics. Many places or spaces are always made to include facilities such as power supply socket. To connect a power source to the device from the wall socket is usually done by connecting both via conductor. This way pose a problem in terms practicality and aesthetics. Connecting cord socket and the appliance is not flexible, and beautiful views, especially if the installationis not good.

Handphone is an electronic telecommunications device that can be carried anywhere and do not need to be connected to the telephone network using a cable. But the cables are still used in the process of charging the battery, with the current technological developments there is a way battery charging is done wirelessly by putting cell phones that want to be charged to the top of the wireless charger pad. By simply putting the phone to the top of the pad is certainly not very good because if the cell phone was shifted or removed from the pad, will cut off the charging power. For that we need a system that can wirelessly charging that its scope covers all directions or $360^{\circ}$, so the better the reach and use.

\subsection{Statement of the Problem} problem:

From the description of the background above, can be identified with the following

1. The use of the cable as the power transmission medium cause problems in flexibility and aesthetics.

2. Handphone is not yet fully portable, because when charging still using a cable. 
3. Transmissionof power to charge handphone in circulation today, still use an antenna with radiation is still in one direction that is towards the top, if it was shifted or moved, the transmitted power will be disconnected.

\subsection{Relevant Literature}

The project to transmit electrical power without any wires, with a smale scale by using solar energy. The power is transferred wirelessly through an inductive coupling as an antenna. The experiments have been conducted and the wireless power transfer can be transfer energy up to $10 \mathrm{~cm}$, with efficiency $0-10 \mathrm{~cm} ; 98.87 \%-40 \%$ with LED as the load. The project used loop antenna to transmit power wirelessly with both antenna face-to-face [1].

The experiment to generate wireless microwave power charging technology in coal mine tunnels, with power characteristics at $2.4 \mathrm{GHz}$ in rectangular mine tunnels. The experiment used two standard half-wave dipole antennas to perform the field experiments in tunnels with different wall materials. The path loss exponents rely heavily on the location of the receiver and antenna polarizations. To obtain more power, the location of the receiver should match the corresponding polarizations [2].

The experiment design on the structure of the resonant coil used in the resonant tank to achieve a significantly high quality factor (Q) above 1000 for the Inductive Power Transfer (IPT).The experimental result show that with a primary coil Q of 1200, the proposed IPT system allows power to be transferred at a maximum air gap distance to coil diameter ratio of 1.46 for a highest efficiency of $87 \%$ at the resonant frequency at $106 \mathrm{KHz}$ [3].

Michael Octova Research (2010) [4], student of electrical engineering, University of Indonesia, with the thesis title "Analisa dan Rancang Bangun Rangkaian Penerima Pada Sistem Transfer Daya Listrik Tanpa Kabel". The research makes a device that can send power wirelessly (wireless power transfer) with the principle of induction magnetic resonance, with three main parts, that is sources of direct current with the output voltage of $12 \mathrm{~V} \mathrm{DC}$, the transmitter circuit which consists of a ACvoltage generator circuit with high frequency of about $1,324 \mathrm{MHz}$, which will transmit the power to the receiver circuit via transmitting antenna shaped loop, and the receiver circuit consist of an LC circuit with a resonance frequency that is equal to the transmitter circuit, receive induction magnetic resonance of the transmitter circuit for receiving power which will be channeled towards the load with the results of the output voltage of $\pm 3 \mathrm{~V}$. The result is a device that can send power to the receiver to supply the load in the form of a lamp with a distance of a few centimeters, and position of transmitting antenna and receiver antenna was face-to-face.

Based on vivanews (2011) [5], with the headline "Peneliti UI Ciptakan Charger Ponsel Nirkabel", that researchers from the University of Indonesia managed to find a new way to transfer electrical energy through a wireless medium (without cable). This smart phone battery could be charged by putting the phone to the top of wireless charger dock named Touchstone. The device consists of four components, that is electricity transmitter, transmitter antenna, receiver antenna, and the receiver circuit. This electric transfer method uses the principle of electromagnetic resonance frequency.

\section{Research Method}

System design is done in two phases: block diagram design and device design. In designing the block diagram, shown blocks that make up the transmitter and receiver. At the transmitter, starting from the resource that provides power to the oscillator to generate an oscillating signal in the form of electric power to be transmitted to the receiver via antenna. At the receiver, the receiver antenna received the power transmitted which is still within the range of magnetic fields generated by transmitter. Received power is still a signal that is oscillated, and to be used as a mobile power supply, rectification process is required in order to become a stable output voltage with less noise. Here is a view of the design of the system block diagram: 


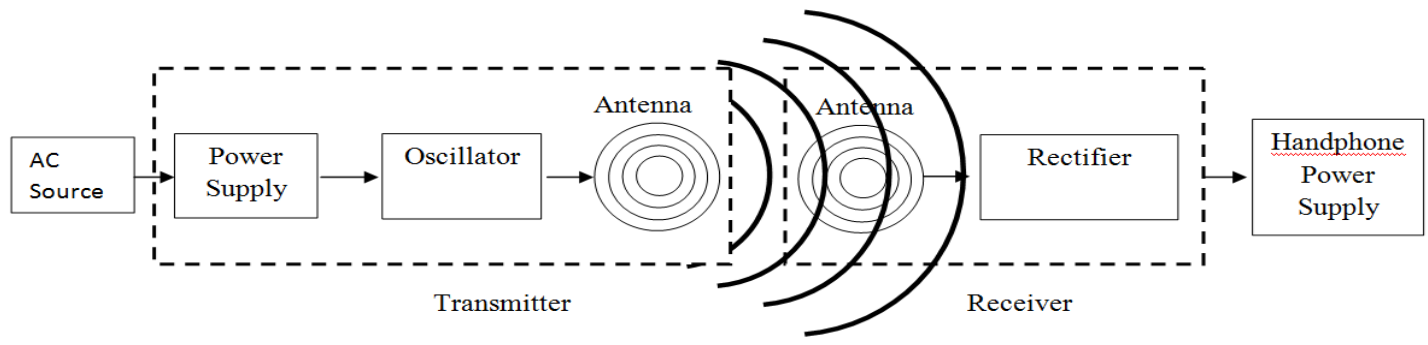

Figure 1. Block diagram ofsystem design of the mobile phone wireless charger

Oscillatoris a circuit that functions to produce a wave or electrical signal periodically with a constant amplitude. Basically DC signalpower supply is converted by an oscillator circuit into AC signal to produce an electrical signal that is periodic with a constant amplitude. The components of the oscillator in this research is the MOSFET IRF $540 \mathrm{~N}, 1 \mathrm{~N} 4148$ diode, $4.7 \mathrm{nF}$ capacitors, inductors, and resistors. These components are assembled into the oscillator circuit shown in the Figure 2.

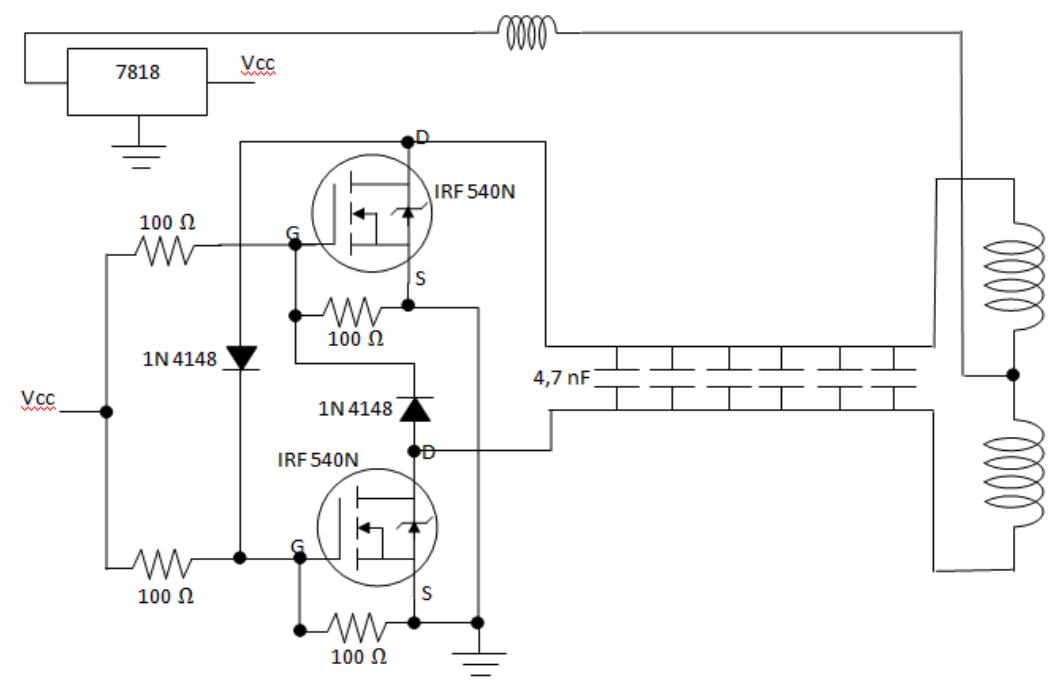

Figure 2. Oscillator Circuit

The design of the receiver consists of three main parts, namely, receiving antenna function to receive the power transmitted from the transmitter, the voltage regulator circuit that serves to stabilize the input voltage to power mobile phones, and USB connectors to connect the receiver with handphone. The components used in the receiver circuit is a 7805 regulator, diode $1 \mathrm{~N} 4148,100 \mu \mathrm{F}$ electrolytic capacitors. These components are assembled into receiver circuit as shown in Figure 3.

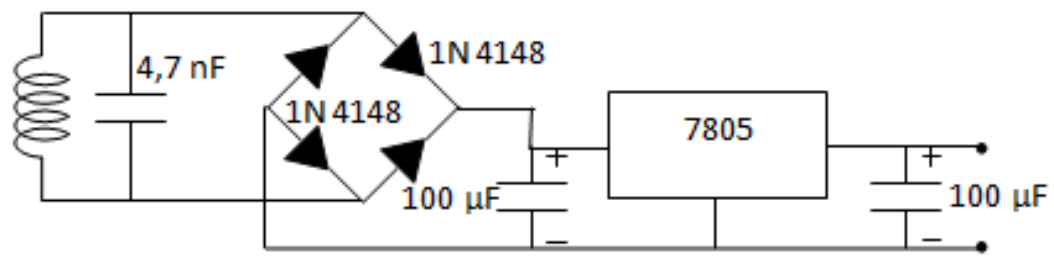

Figure 3. Receiver Circuit 


\section{Result and Analysis}

\subsection{Transmitter Testing}

The results of measurements of voltage and current at the input transmitter using digital multimeter is, the transmitting antenna input current $=1.19 \mathrm{~A}$, and the voltage at the transmitting antenna input $=2,57 \mathrm{~V}$. By knowing the voltage and current values, then the value of the power can be calculated by equation $\mathrm{P}=\mathrm{IV}$, the result is $\mathrm{P}=1.19 \times 2.57 \mathrm{~A} \mathrm{~V}=3.058 \mathrm{~W}$. in addition to measuring voltage and current, frequency measurements to determine how much the frequency used on the power transmitter system's without wires. Frequency measurements done using Picoscope. The results of frequency measurements by using picoscope shown in Figure 4.

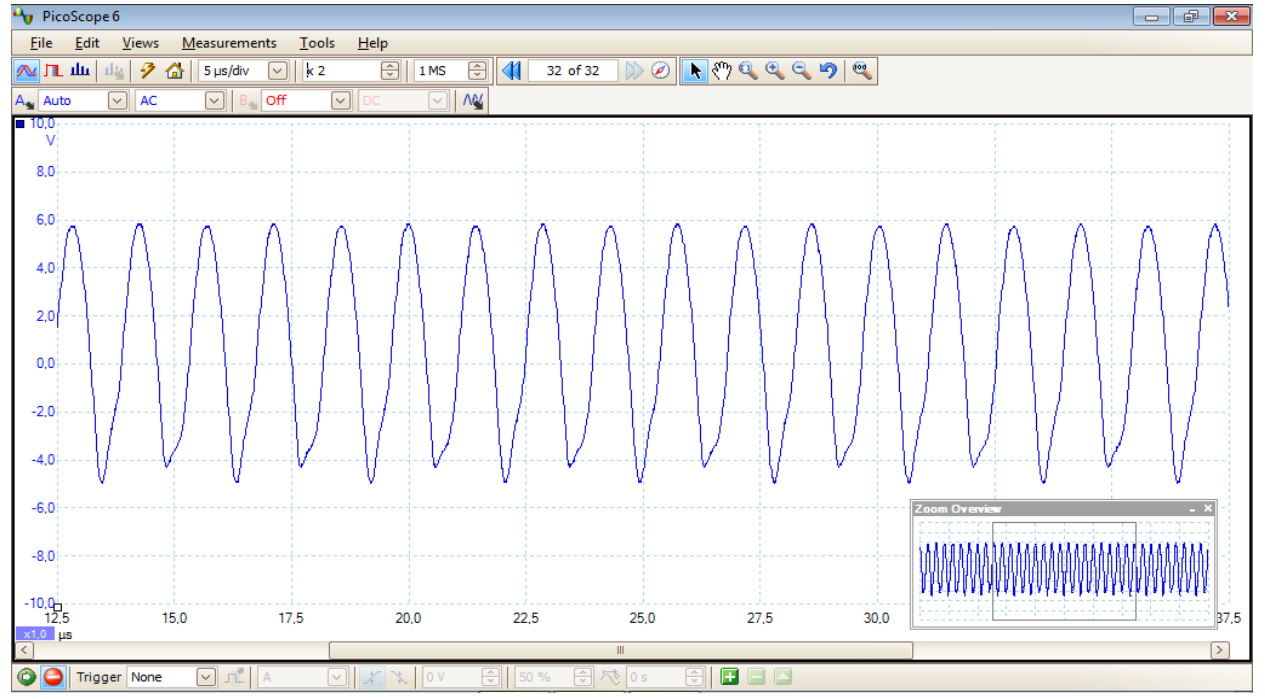

Figure 4. Waveform Measurement Results of Output Transmitter Frequency Using PicoScope

From the picture above is known for the distance between wave crests is $1.4 \mu \mathrm{s}$, the time is the time the wave used to reach a full wave or also called the period (T). Value of period $(T)$ can be used to calculate the value of frequency by the equation $f=1 / T$. The measured frequency value at the transmitter circuit is

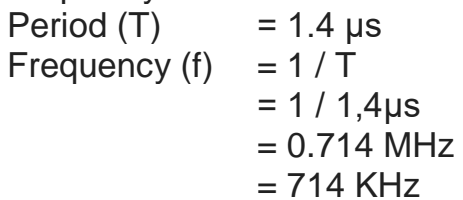

So the transmitter working frequencies calculation results is equal to $714 \mathrm{KHz}$, the amplitude of the voltage transmitted is $5.9 \mathrm{~V}$.

\subsection{Receiver Testing}

The results of the measurements used to determine receiver input waveform using picospcopeis shown in Figure 5. Picture in Figure 5 shows the measurement result of receiver input using picoscope. The input will then be rectified and stabilized by the rectifier, and a voltage regulator. Measurements with picoscope to determine the output receiver that will be connected to the handphone via the USB connector is shown in Figure 6. 


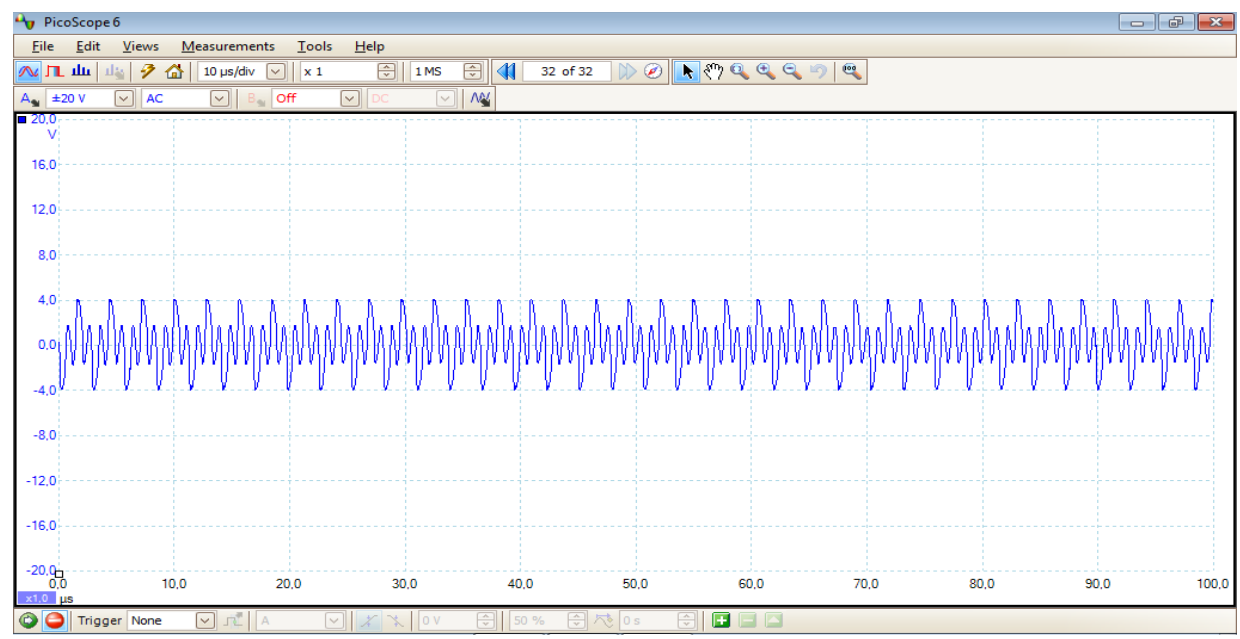

Figure 5. Waveform Measurement Results of Receiver Input Frequency using Pico Scope

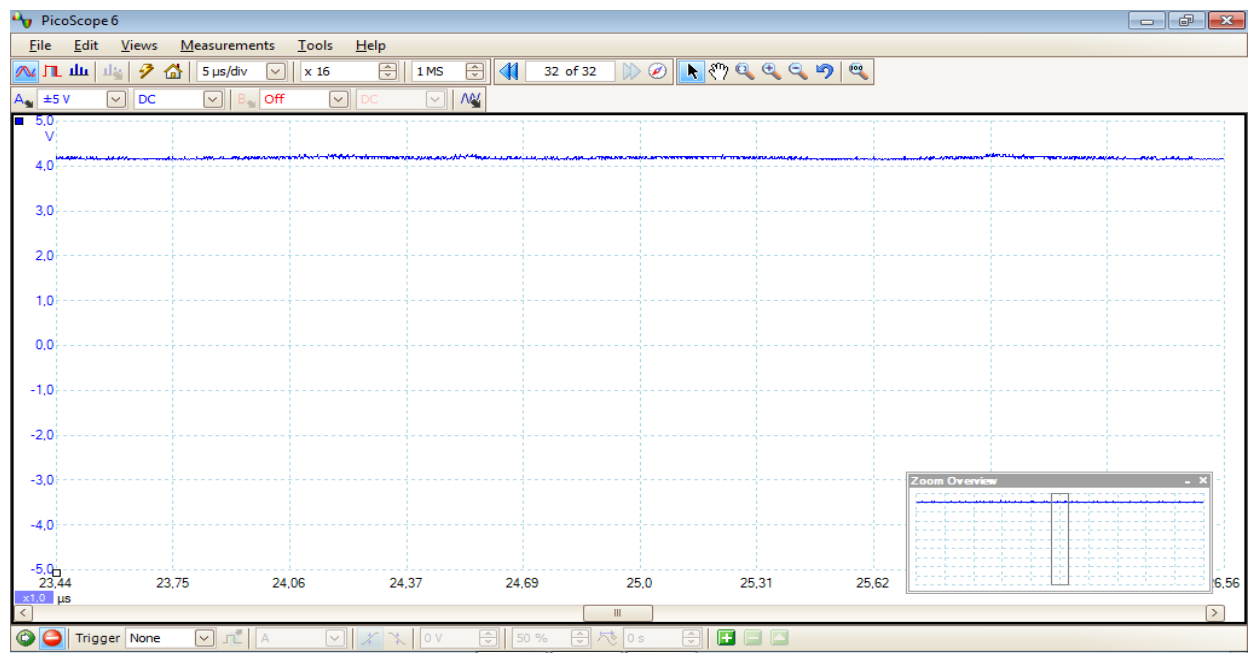

Figure 6. Waveform of Receiver Output that has been Rectified and Stabilized for Handphone Input

Picoscope measurement results show that the input oscillating voltage of receiver has been rectified and stabilized, so that the output voltage of the receiver to be stable with a wave amplitude of about 4.1 volts. The results of measurements of voltages and currents at the receiver input using a digital multimeter is the receiver input current $=14.9 \mathrm{~mA}$, the receiver input voltage $=3,94 \mathrm{~V}$. By knowing the voltage and current values, then the value of the power can be calculated by the equation $P=I . V$, is the calculation of output power receiver is as follows Power $(P)=I . V=14.9 \mathrm{~mA} \times 3.94 \mathrm{~V}=58,706 \mathrm{~mW}$. So the received power receiver is $58.706 \mathrm{~mW}$.

To determine the effectiveness of the transmission of power in this system, is calculated using the following equation Effectiveness of transmission of power $=$ (Power Receiver) $/$ (Power Transmitter) $\times 100 \%$, Effectiveness of delivery of power $=58.706 / 3058 \times 100 \%=$ $1.919 \%$, so the effectiveness of maximum power delivery in system of wireless power transmitter are at $1.919 \%$.

\subsection{Antenna Testing}

Antenna tests conducted to determine antenna inductance and angle radiation range of antenna generated by wireless power system's transmitter. Inductance was measured using 
LCR meter on a scale of $20 \mathrm{mH}$. The result was featuredby LCR meter that antenna inductance is $0.01 \mathrm{mH}$ or $10 \mu \mathrm{H}$. Inductance of the antenna is calculated using equationwith the permeability of free space $(\mu 0)=4 \pi 10-7$, number of turns $(N)=6$, coil diameter $(d)=4.8 \mathrm{~cm}(\mathrm{r}=$ $2,4 \mathrm{~cm})$, inner core area $(\pi \mathrm{r} 2)=18.08 \times 10-4 \mathrm{~m} 2$, and length of the coil $(\mathrm{I})=0.5 \mathrm{~cm}(5 \times 10-3 \mathrm{~m})$ is as follows

$$
\begin{aligned}
\mathrm{L} & =\mu_{0} \frac{N^{2} \cdot A}{l} \\
& =4 \pi 10^{-7} \frac{6^{2} \times 18,08 \times 10^{-4}}{5 \times 10^{-3}} \\
& =1.635 \times 10^{-8} \mathrm{H} \\
& =16,35 \mu \mathrm{H}
\end{aligned}
$$

Thus, the results of inductance calculation is $16.35 \mu \mathrm{H}$, approaching inductance measurement results $10 \mu \mathrm{H}$ with a difference of $6.35 \mu \mathrm{H}$.

Antenna radiation testing conducted by the state without obstacle. Directions testing of antena is in the front, back, right and the left of transmitter. Testing of antenna shown the following Figure 7.
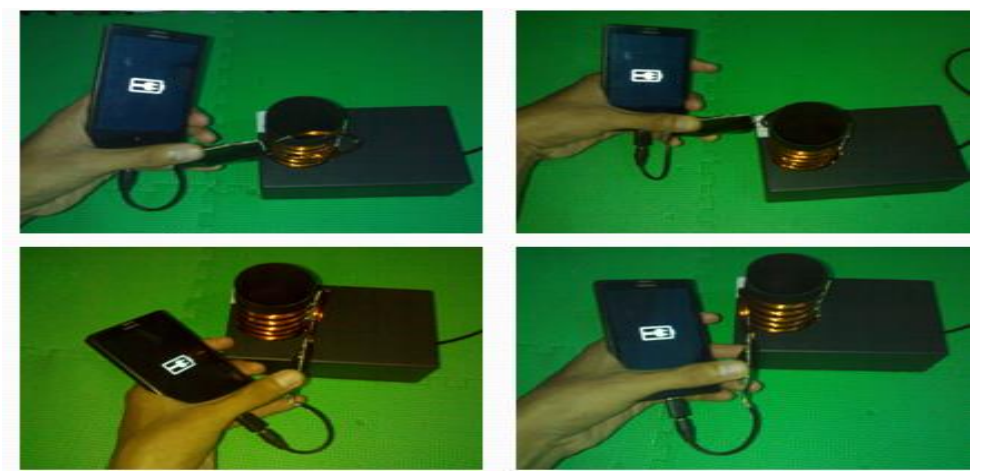

Figure 7. Testing of Antennas with Different Directions

The results of antenna testing with the position of the receiver that are in different position of thetransmitter is the transmitter antennacan transmit power to all directions horizontally or 360 degrees.

\subsection{Power Testing Against Time When Charging}

This test was conducted to determine the voltage $(\mathrm{V})$, current $(\mathrm{mA})$, and power $(\mathrm{mW})$ versus time (in minutes). Tests conducted for 20 minutes, with data taking within 30 seconds ( 0.5 minutes). The test results are presented in the following Figure 8.

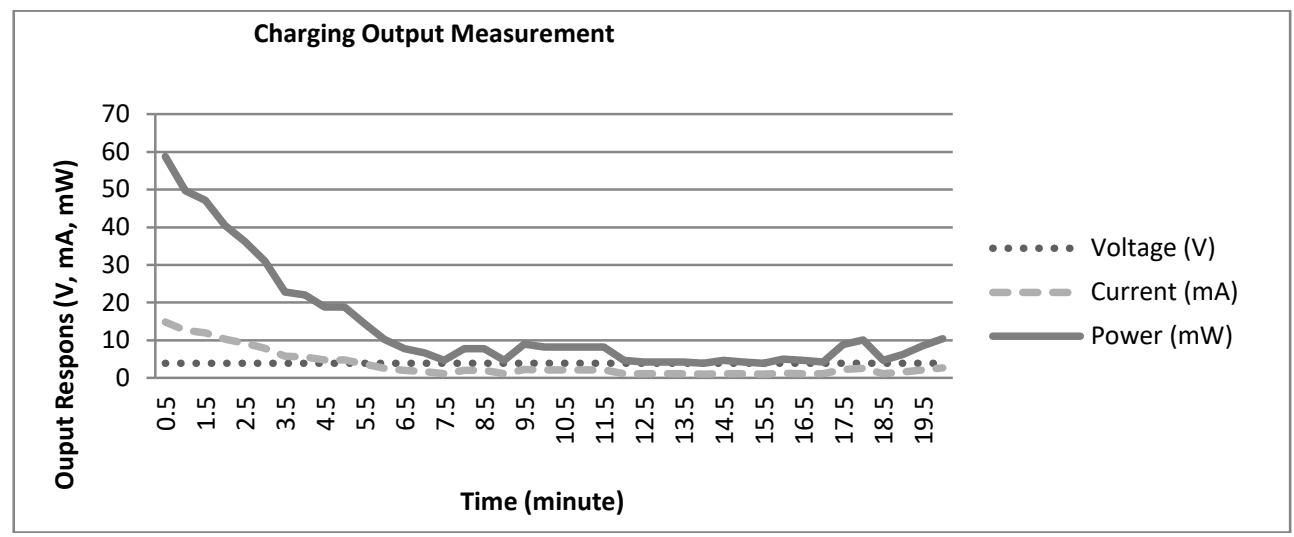

Figure 8. Test Result Chartof Voltage (V) Current (mA), Power (mW), Against Time (minute) 
From the results of Voltage, Current, and power versus time are presented in Figure 8, it can be seen that the output voltage is relatively stable and it ranged at $3.9 \mathrm{~V}$, the output current is greater initially,then be small at the end of the charging. This charging using constant voltage, so the voltage required to remain stable for this type of lithium-ion batteries

\subsection{Receiver Power Testing with the Number of Receiver Antenna Turns Changing}

This section describes the results of measurement and calculation power at the receiver with the number of antenna coil. The results of measurements and calculations are shown in Table 1.

Table 1. Power Measurement and Calculation Results, and Calculation of Gain Antenna (Gt)

\begin{tabular}{ccccccc}
\hline \multicolumn{7}{c}{ and Receiver (Gr) Using Friis Equation } \\
\hline $\begin{array}{c}\text { Distance } \\
(\mathrm{cm})\end{array}$ & $\begin{array}{c}\text { Voltage } \\
(\mathrm{V})\end{array}$ & $\begin{array}{c}\text { Current } \\
(\mathrm{mA})\end{array}$ & $\begin{array}{c}\text { Power of } \\
\text { Measurement } \\
(\mathrm{mW})\end{array}$ & $\begin{array}{c}\text { Power of } \\
\text { Calculation } \\
(\mathrm{mW})\end{array}$ & $\begin{array}{c}\text { Antenna } \\
\text { Gain, Gt } \\
(\mathrm{dB})\end{array}$ & $\begin{array}{c}\text { Antenna } \\
\text { Gain, Gr } \\
(\mathrm{dB})\end{array}$ \\
\hline 0.2 & 2.64 & 16.71 & 44 & 91.50763 & -52.6202 & -52.6202 \\
0.5 & 2.46 & 9.76 & 24 & 14.64122 & -49.9618 & -49.9618 \\
1 & 2.07 & 5.73 & 12 & 3.660305 & -48.4828 & -48.4828 \\
1.5 & 1.76 & 2 & 3.52 & 1.626802 & -49.3598 & -49.3598 \\
2 & 1.27 & 0.13 & 0.1651 & 0.915076 & -54.7544 & -54.7544 \\
2.5 & 0.98 & 0 & 0 & 0.585649 & - & - \\
3 & 0.83 & 0 & 0 & 0.406701 & - & - \\
3.5 & 0.36 & 0 & 0 & 0.2988 & - & - \\
4 & 0.24 & 0 & 0 & 0.228769 & - & - \\
\hline
\end{tabular}

In Table 2, there is difference between power of measurement and calculation, because the calculation gain in every measurement ofdistance results different. Power calculation use the mean of gain that is -51.0358 . Receiver with 6 turns equals to transmitter coil, result maximum voltage received. Data in Table 2 then displayed in the following chart

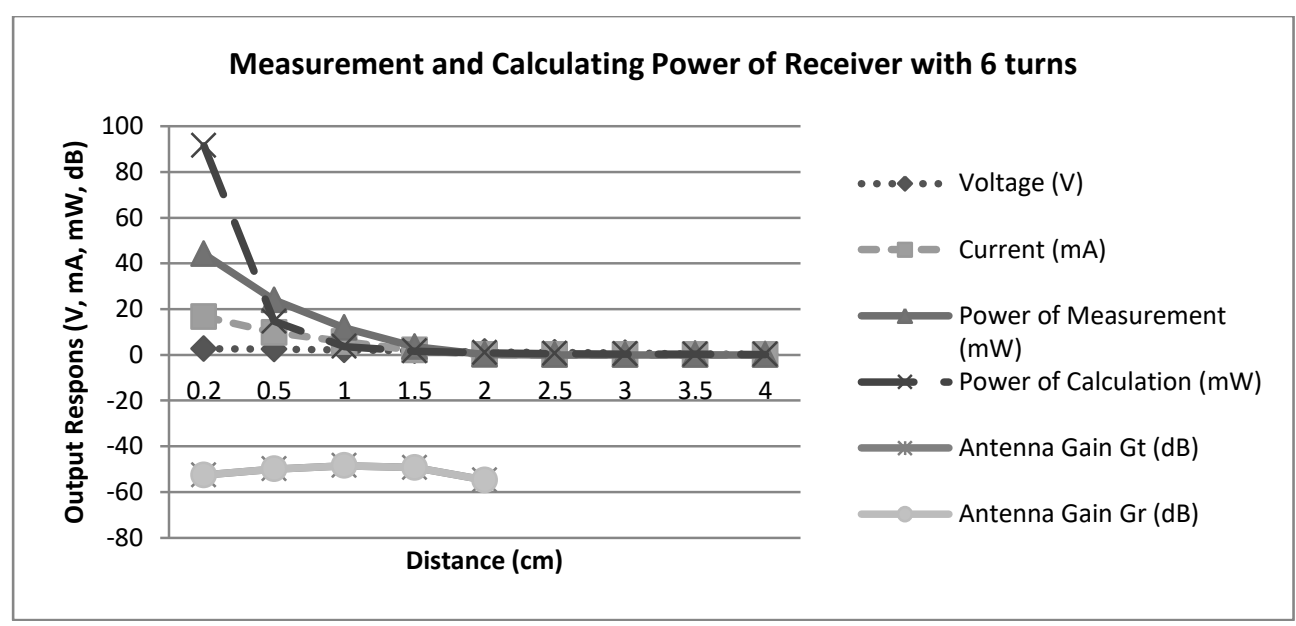

Figure 9. Chartof Measurement Result and Power Calculation, and Calculation of Transmitter Antenna Gain and Receiver Antenna Gain with 6 Turnsof Antenna

\subsection{Receiver Power Testing with the Number of Transmitter Capacitor Changing}

This section describes the results of measurement and calculation power at the receiver with the 5 transmitter'scapacitors. The results of measurements and calculations are shown infollowing Table 2. 
Table 2. Power Measurement and Calculation Results, and Calculation of Gain Antenna (Gt) and Receiver (Gr) Using Friis Equation

\begin{tabular}{cccccrr}
\hline $\begin{array}{c}\text { Distance } \\
(\mathrm{cm})\end{array}$ & Voltage $(\mathrm{V})$ & $\begin{array}{c}\text { Current } \\
(\mathrm{mA})\end{array}$ & $\begin{array}{c}\text { Power of } \\
\text { Measurement } \\
(\mathrm{mW})\end{array}$ & $\begin{array}{c}\text { Power of } \\
\text { Calculation } \\
(\mathrm{mW})\end{array}$ & $\begin{array}{c}\text { Antenna } \\
\text { Gain Gt }(\mathrm{dB})\end{array}$ & $\begin{array}{c}\text { Antenna } \\
\text { Gain Gr } \\
(\mathrm{dB})\end{array}$ \\
\hline 0.2 & 2.87 & 17.2 & 49 & 210.3378 & -52.376 & -52.376 \\
0.5 & 2.78 & 7.3 & 20 & 33.65405 & -50.3268 & -50.3268 \\
1 & 2.73 & 5.9 & 16 & 8.413511 & -47.8183 & -47.8183 \\
1.5 & 2.67 & 3.7 & 10 & 3.739338 & -47.1189 & -47.1189 \\
2 & 2.62 & 2.2 & 6 & 2.103378 & -47.0395 & -47.0395 \\
2.5 & 2.28 & 1.4 & 3 & 1.346162 & -47.3537 & -47.3537 \\
3 & 2.01 & 0.1 & 0.201 & 0.934835 & -52.5662 & -52.5662 \\
3.5 & 1.47 & 0 & 0 & 0.686817 & - & - \\
4 & 1.07 & 0 & 0 & 0.525844 & - & - \\
\hline
\end{tabular}

In table 2, there is difference between power of measurement and calculation, because the calculation gain in every measurement of distance results different. Power calculation use the mean of gain that is -49.2285 . Transmitter with 5 capacitors, result maximum power received by receiver. Data in Table 3then displayed in the following chart.

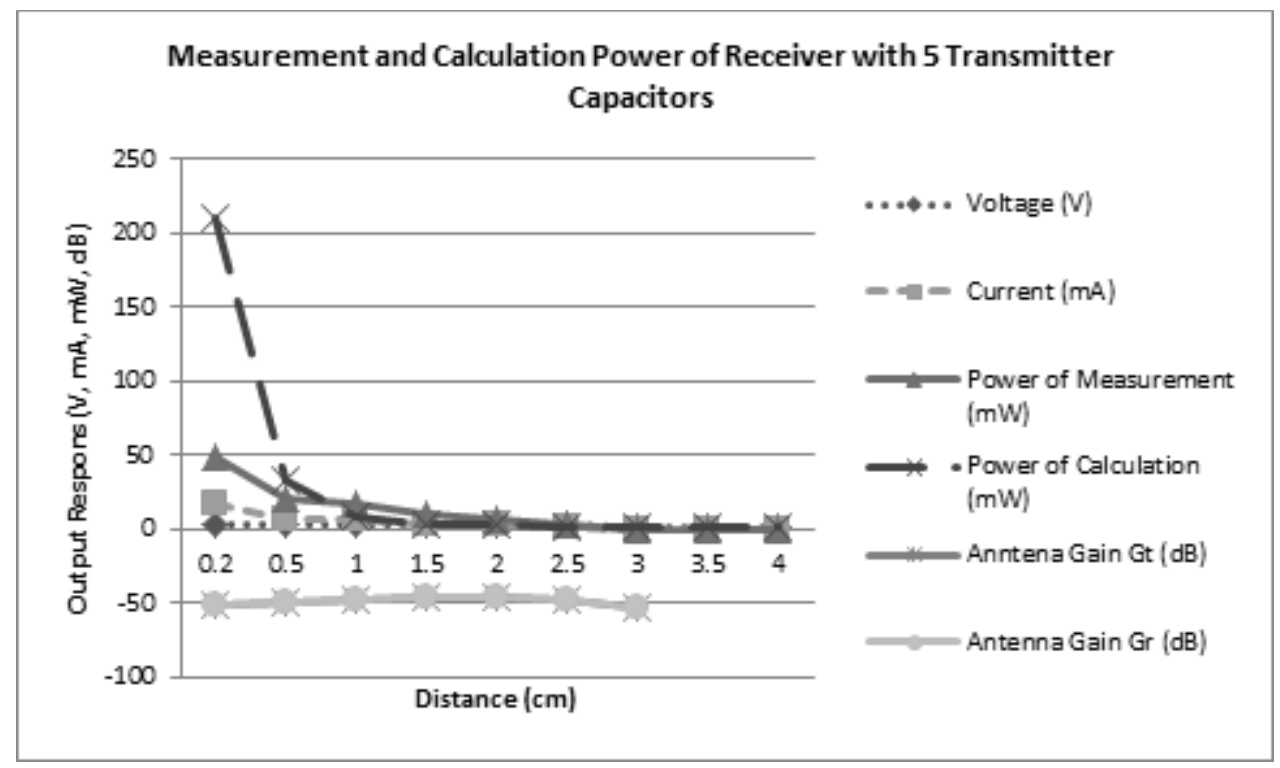

Figure 10. Chartof Measurement Result and Power Calculation, and Calculation of Transmitter Antenna Gain and Receiver Antenna Gain with 5 Capacitors of Transmitter

\section{Conclusion}

Based on the results of this research and discussion can be concluded as follows:

1. It has been successfully constructed system that can wirelessly charging handphone using omnidirectional antenna.

2. Transmitter antenna can send power to all directions or 360 degrees horizontally.

3. Power is transmitted from the transmitter is equal to 3,058 watts, with the frequency of 714 $\mathrm{KHz}$.

4. The calculation result transmitting antenna gain and receiver antenna gain at each measurement are the same value.

5. Maximum power transmission occurs if the number of receiver antenna turns is at or near the amount of the transmitter antenna turns, and the number of transmitter capacitors approaching 5 capacitors. 


\section{References}

[1] M Fareq, M Fitra, M Irwanto, Syafruddin HS, N Gomesh, M Rozailan, M Arinal, YM Irwan, J Zarinatul. Wireless Power Transfer by Using Solar Energy. TELKOMNIKA. 2014; 12(3): 519-524.

[2] Xiaoming Liu, Enjie Ding, Duan Zhao, Youfang Yang. Power Characteristics of Wireless Charging for Sensor Networks in Tunnels. TELKOMNIKA. 2015; 13(4): 1180-1186.

[3] Qifan Li, Yung C. Liang. An Inductive Power Transfer System with A High-Q Resonant Tank For Mobile Device Charging. IEEE transactions on power electronics. 2015; 30(11): 6203-6212.

[4] Octova M. Analysis and Design of Receiver Circuit on Wireless Power Transfer System. Depok: Universitas Indonesia. 2010.

[5] Darmawan I. UI Researchers Create Wireless Cell Phone Charger. from: http://teknologi.news.viva.co.id/news/read/208207-peneliti-ui-buat-pengecas-ponsel-nirkabel. 2011. 